\title{
BMJ Open Prevalence and determinant factors of mental health problems among healthcare professionals during COVID-19 pandemic in southern Ethiopia: multicentre cross- sectional study
}

Mohammed Ayalew (D) ,' Bedilu Deribe, ${ }^{1}$ Yacob Abraham, ${ }^{1}$ Yared Reta (D) , Fikru Tadesse, ${ }^{1}$ Semira Defar, ${ }^{2}$ Dawit Hoyiso, ${ }^{1}$ Tebeje Ashegu ${ }^{2}$

To cite: Ayalew M, Deribe B, Abraham Y, et al. Prevalence and determinant factors of mental health problems among healthcare professionals during COVID-19 pandemic in southern Ethiopia: multicentre crosssectional study. BMJ Open 2021;11:e057708. doi:10.1136/ bmjopen-2021-057708

\section{- Prepublication history for} this paper is available online. To view these files, please visit the journal online (http://dx.doi. org/10.1136/bmjopen-2021057708).

Received 27 September 2021 Accepted 08 December 2021

\section{Check for updates}

(c) Author(s) (or their employer(s)) 2021. Re-use permitted under CC BY-NC. No commercial re-use. See rights and permissions. Published by BMJ.

${ }^{1}$ School of Nursing, Hawassa University College of Medicine and Health Sciences, Hawassa, Sidama, Ethiopia

${ }^{2}$ Department of Midwifery, Hawassa University College of Medicine and Health Sciences, Hawassa, Sidama, Ethiopia

Correspondence to Mohammed Ayalew; mameayale@gmail.com

\section{ABSTRACT}

Objective To assess the prevalence of depression, anxiety and stress and its determinant factors during COVID-19 pandemic among healthcare professionals in southern Ethiopia.

Design Multi-centre cross-sectional study.

Setting and study period Randomly selected public hospitals in Sidama, southern Ethiopia between 25 September 2020 and 25 0ctober 2020.

Participants 387 healthcare professionals were randomly selected.

Outcome measures Prevalence and determinant factors of depression, anxiety and stress was assessed.

Result Depression, anxiety and stress prevalence were shown to be $50.1 \%$ (95\% confidence interval (Cl) $45.0 \%$ to $55.0 \%$ ), $55.0 \%$ (95\% Cl $51.1 \%$ to $59.9 \%$ ) and $38.5 \%$ (95\% Cl $33.6 \%$ to $43.2 \%$ ), respectively. Being female (adjusted odd ratio (AOR) 3.71, 95\% Cl 2.31 to 5.97), married (AOR 2.28, $95 \% \mathrm{Cl} 1.34$ to 3.86 ), living alone (AOR 1.87, 95\% Cl 1.09 to 3.20 ), nurses (AOR 2.94, 95\% $\mathrm{Cl} 1.44$ to 5.99) and working in inpatients (AOR $0.53,95 \% \mathrm{Cl} 0.29$ to 0.93 ) were significantly associated with depressive symptoms. Moreover, older age groups (AOR 3.15, 95\% Cl 1.04 to 6.56), females (AOR 3.25, $95 \% \mathrm{Cl} 2.01$ to 5.25 ), married (AOR 1.69, 95\% Cl 1.01 to 2.87) and nurses (AOR 3.32, 95\% $\mathrm{Cl} 1.63$ to 6.78 ) were significantly associated with symptoms of anxiety. Stress symptoms were significantly high among females (AOR 2.47, $95 \% \mathrm{Cl} 1.53$ to 3.97), married (AOR 2.77, 95\% Cl 1.60 to 4.78), living alone (AOR 2.01, 95\% $\mathrm{Cl} 1.15$ to 3.52), nurses (AOR 2.34, 95\% Cl 1.11 to 4.92) and working in units other than emergency (inpatient (AOR 0.32, 95\% $\mathrm{Cl} 0.18$ to 0.57) and other units (AOR 0.48, 95\% $\mathrm{Cl} 0.25$ to 0.95)). Conclusion The current study found that healthcare professionals have high levels of depression, anxiety and stress symptoms. Sex, age, marital status, type of profession, living status and working environment were significant factors for mental health problems in healthcare professionals during the pandemic. Healthcare professionals require mental health support at which monitoring and control can be performed during and after the pandemic.
Strengths and limitations of this study

- This study assessed the depression, anxiety and stress among Ethiopian healthcare professionals during the COVID-19 pandemic.

- Mental health problems were assessed solely through self-administered questionnaires rather than through a psychiatric interview.

- This is a cross-sectional study that does not determine cause and effect relationship.

- No information on the type of mental health support received by healthcare workers could be obtained.

\section{INTRODUCTION}

COVID-19 pandemic, which began in China, continues to pose a global health hazard. ${ }^{1}$ The COVID-19 outbreak was declared as a public health emergency of worldwide concern by WHO on 30 January $2020 .^{2}$ Globally, there have been 236875393 COVID-19 cases and 4715147 deaths as of 31 October 2021. In Ethiopia, there were 365167 confirmed COVID-19 cases and 6459 deaths in the country by the end of October 2021 with a $1.77 \%$ case fatality rate. Ethiopia is now ranked fifth in Africa in terms of confirmed COVID-19 infections and deaths. ${ }^{3}$

In addition to physical pain, COVID-19 causes substantial psychological stress and other health-related difficulties. Healthcare workers (HCWs) are no exception, as they are responsible for infected patients, have frequent interactions with their families/ relatives and are occasionally scrutinised by the public. ${ }^{4}$ Healthcare professionals (HCPs) around the world have been subjected to excessive workloads and psychological stress as a result of the massive number of cases 
and deaths associated with this pandemic, which has increased the burden on the healthcare system, potentially resulting in negative consequences for society. ${ }^{5} \mathrm{HCPs}$ are directly involved in the diagnosis, treatment, and care of COVID- 19 patients on a daily basis. They spend an average of 16 hours per day caring for COVID-19-infected patients, which is an exhausting workload. ${ }^{6}$ Furthermore, the rising number of confirmed and suspected cases, the depletion of personal protective equipment (PPE), the lack of specific drugs available for COVID-19 treatment and feelings of being under supported by healthcare delivery system are all thought to contribute to HCPs' psychological burdens. ${ }^{7}$

A recent systematic review, during the COVID-19 pandemic, the pooled prevalence of anxiety, depression and distress among HCPs accounted to $40 \%, 37 \%$ and $37 \%$, correspondingly. ${ }^{8}$ According to a recent study including 1563 health professionals, more than half $(50.7 \%)$ of the participants reported depressive symptoms, $44.7 \%$ experience anxiety and $36.1 \%$ have sleep disturbances. ${ }^{9}$ During the initial outbreak of COVID-19, a survey was conducted in China. According to the findings of this study, $53.8 \%$ of respondents rated the psychological impact of the outbreak as moderate to severe; $16.5 \%$ reported moderate to severe depressive symptoms; $28.8 \%$ reported moderate to severe anxiety symptoms and $8.1 \%$ reported moderate to severe stress levels. ${ }^{10}$ Another study in Singapore found that $14.5 \%$ of participants tested positive for anxiety, $8.9 \%$ for depression, $6.6 \%$ for stress and $7.7 \%$ for clinical concern of post-traumatic stress disorder (PTSD). Anxiety was more prevalent among nonmedical HCPs than among medical personnel (20.7\% vs $10.8 \%){ }^{11}$

Recent studies in different parts of Ethiopia indicated that HCPs were experience to various mental health problems following COVID-19 pandemic. For instance, a study conducted in Ethiopia showed that about onefourth $(26.8 \%)$ experience anxiety, ${ }^{12} 78.3 \%$ developed psychological distress ${ }^{13}$ and about half $(51.6 \%)$ experienced perceived stress. ${ }^{14}$ Another similar study conducted in northern Ethiopia also found out that $58.2 \%, 64.7 \%$ and $63.7 \%$ HCPs experienced symptoms of depression, anxiety and stress, respectively. ${ }^{15}$

Psychological difficulties are most likely to occur for HCPs working in emergency areas, intensive care units (ICUs) and insulation rooms. ${ }^{16}$ According to a study conducted in Singapore, doctors and single people are more likely to acquire psychiatric symptoms than nurses and married people. ${ }^{17}$ In addition, a lack of social support and communication, as well as maladaptive coping and a lack of training, are all key risk factors for psychological morbidity. ${ }^{16}$

HCPs often have several psychological problems in a high-pressure, high-risk antipandemic setting. ${ }^{18}$ As a result, psychological evaluation and intervention in victims and rescuers, such as medical personnel and volunteers, is critical for pandemic control. This concept is advantageous not only for early intervention and psychological intervention, but also for significantly improving pandemic control and hastening social recovery. ${ }^{19}$ As a result, HCPs' moral and mental health should be protected, as this can have an impact on the success of healthcare delivery and COVID-19 control.

The mental health problems of HCPs in Ethiopia during the peak of the COVID-19 pandemic were yet unknown. This is especially important given the unpredictability of such an outbreak. This study investigates the mental health impact of the COVID-19 epidemic in southern Ethiopia for these reasons. As the COVID-19 pandemic spreads across Ethiopia, this could help government organisations and HCPs protect the community's mental health. Thus, the aim of this study was (1) to assess prevalence of depression, anxiety, stress symptoms and its determinant factors among HCPs and (2) to describe common causes of fear/anxiety among HCPs during COVID-19 pandemic in southern Ethiopia.

\section{MATERIALS AND METHODS}

\section{Study area}

This study was conducted at selected public hospitals (Hawassa University Comprehensive Specialised Hospital, Adare General Hospital, Leku Primary Hospital and Yirgalem General Hospital) in Sidama National Regional State, southern Ethiopia.

\section{Study design and period}

Institution-based cross-sectional study design was conducted among HCPs between 25 September 2020 and 25 October 2020.

\section{Study subjects}

This study was conducted among front-line HCPs working in medical and surgical inpatient units, ICUs, emergency departments and outpatient units. In addition, non-frontline health professionals who are working at regular chronic care clinic, laboratory, pharmacy, delivery, etc units were included.

\section{Sample size and sampling procedure}

The required sample size was determined using single population proportion formula

$$
\mathrm{n}=\left(\mathrm{Z}^{2} * \mathrm{P}(1-\mathrm{P}) / \mathrm{d}^{2}\right)
$$

where $\mathrm{n}$ is the sample size, $\mathrm{z}$ is the standard normal score set at $1.96, \mathrm{~d}$ is the desired degree of accuracy and $\mathrm{p}$ is the estimated proportion of the target population. Due to the lack of previous research to inform our expected sample proportion ( $\mathrm{p})$, we use a value that gives our sample size maximum that is, $\mathrm{p}=0.5$. Then by taking $\mathrm{p}=50 \% . \mathrm{Z}=1.96$ and $\mathrm{w}=5 \%$, the computed sample size was 384 and by taking $10 \%$ non-response rate, the total sample size computed was 422 . The overall sample size was proportionally allocated to each health institution. Then simple random sampling method was used to select the study participants by taking the lists from the human resource office of each respective health institution. 


\section{Data collection tools}

Data were collected by using structured self-administered questionnaire. The questionnaire consists three parts that is, sociodemographic characteristics of participants, items to assess common sources of fear/anxiety in HCPs and items to assess dependent variables. The 21-items Depression, Anxiety and Stress Scale (DASS-21) tool was used to assess depression, anxiety and stress symptoms.

Mental health status was measured using the DASS-21 and calculations of scores were based on the previous study. ${ }^{20}$ The total depression subscale score was divided into normal (0-4), mild,${ }^{56}$ moderate, ${ }^{7-10}$ severe ${ }^{11-13}$ and extremely severe (14+). The total anxiety subscale score was divided into normal (0-3), mild, ${ }^{45}$ moderate, ${ }^{67}$ severe ${ }^{89}$ and extremely severe $(10+)$. The total stress subscale score was divided into normal $(0-7)$, mild, ${ }^{89}$ moderate, ${ }^{10-12}$ severe $^{13-16}$ and extremely severe $(17+)$. The cut-off score for depression, anxiety and stress were $4 / 5,3 / 4$ and $7 / 8$, respectively. ${ }^{21}$ DASS had a very good internal consistency in this study with a cronbach's $\alpha$ of 95.9 .

Four nurses were involved in data collection after receiving a 2-day intensive training on data collection techniques. A pretest was performed in $5 \%$ of the sample to identify potential problems with data collection instruments and to ensure the consistency of the questionnaires. During the data collection process, supervisors checked each questionnaire for completeness on a daily basis.

\section{Data processing and analysis}

Collected data were entered to Epi-data V.3.1 and exported to SPSS V.24 for windows for analysis. Descriptive statistics were used to identify distributions of sociodemographic characteristics of the study participants. The magnitude of depression, anxiety and stress were described as a percentage. Logistic regression analyses with 95\% CI were used to see the association between each independent and outcome variable. Finally, those variables which showed statistical significance at $\mathrm{p}<0.05 \%$ and $95 \%$ CI in the final model was reported as independently associated with the outcome variables. The model fitness test was checked using the Hosmer and Lemeshow goodness of fit test. The $\mathrm{p}$ values of Hosmer-Lemeshow goodness-of-fit test were greater than 0.05 for all the models.

\section{Patients and public involvement}

Patients and the public were not involved in this study, including the recruitment, data collection, analysis, interpretation and dissemination of the results.

\section{RESULTS}

\section{Sociodemographic characteristics}

A total of 387 health professionals participated in the study. The majority of study participants $227(58.7 \%)$ were male, $233(60.2 \%)$ were aged $26-35$ years, nearly half $191(49.4 \%)$ were married, about three-fourth 298 (77.0) had BSc degree, $230(59.4 \%)$ had $\leq 5$ years of experience,
Table 1 Sociodemographic characteristics of the study participants during COVID-19 pandemic in selected hospitals of Sidama National Regional State, $2020(n=387)$

\begin{tabular}{|c|c|c|c|}
\hline Variable & Category & Frequency & $\%$ \\
\hline \multirow[t]{2}{*}{ Sex } & Male & 227 & 58.7 \\
\hline & Female & 160 & 41.3 \\
\hline \multirow[t]{3}{*}{ Age } & $<25$ years & 112 & 28.9 \\
\hline & 26-35 years & 233 & 60.2 \\
\hline & $\geq 36$ years & 42 & 10.9 \\
\hline \multirow[t]{3}{*}{ Marital status } & Single & 185 & 47.8 \\
\hline & Married & 191 & 49.4 \\
\hline & Divorced & 11 & 2.8 \\
\hline \multirow[t]{4}{*}{ Religion } & Protestant & 189 & 48.8 \\
\hline & Orthodox & 159 & 41.1 \\
\hline & Muslim & 23 & 5.9 \\
\hline & Others* & 16 & 4.1 \\
\hline \multirow{3}{*}{$\begin{array}{l}\text { Educational } \\
\text { status }\end{array}$} & Diploma & 47 & 12.1 \\
\hline & $\begin{array}{l}\text { BSc degree/ } \\
\text { equivalent }\end{array}$ & 298 & 77.0 \\
\hline & $\begin{array}{l}\text { MSc degree or } \\
\text { above }\end{array}$ & 42 & 10.9 \\
\hline \multirow{2}{*}{$\begin{array}{l}\text { Average } \\
\text { monthly } \\
\text { income }\end{array}$} & $<7000$ ETB & 233 & 60.2 \\
\hline & $\geq 7000$ ETB & 154 & 39.8 \\
\hline \multirow{3}{*}{$\begin{array}{l}\text { Work } \\
\text { experience in } \\
\text { years }\end{array}$} & $\leq 5$ years & 230 & 59.4 \\
\hline & $6-10$ years & 121 & 31.3 \\
\hline & $\geq 11$ years & 36 & 9.3 \\
\hline \multirow{2}{*}{$\begin{array}{l}\text { Place of } \\
\text { residence }\end{array}$} & Rural & 72 & 18.6 \\
\hline & Urban & 315 & 81.4 \\
\hline \multirow[t]{3}{*}{ Living status } & With family & 224 & 57.9 \\
\hline & Alone & 143 & 37.0 \\
\hline & With others & 20 & 5.3 \\
\hline \multirow[t]{3}{*}{ Profession } & Physician & 88 & 22.7 \\
\hline & Nurses & 197 & 50.9 \\
\hline & $\begin{array}{l}\text { Other } \\
\text { professionals }\end{array}$ & 102 & 26.4 \\
\hline \multirow{4}{*}{$\begin{array}{l}\text { Working } \\
\text { environment }\end{array}$} & Emergency & 138 & 35.7 \\
\hline & Inpatient units & 120 & 31.0 \\
\hline & OPD & 58 & 15.0 \\
\hline & Otherst & 71 & 18.3 \\
\hline
\end{tabular}

${ }^{*}$ Catholic, traditional.

†Delivery, laboratory, pharmacy, ART(antiretroviral)clinics, TB (tuberculosis) clinics, etc.

ART, antiretroviral; BSc, Bachelor of Science; ETB, Ethiopian Birr; MSc, Master of Science; OPD, outpatient department; TB, Tuberculosis.

$224(57.9 \%)$ were living with their family, half 197 $(50.9 \%)$ were nurses by profession and about one-third $138(35.7 \%)$ were working at emergency department as described in table 1. 
Table 2 What do you think you are most concerned about as a source of fear or anxiety? $(\mathrm{N}=387)$

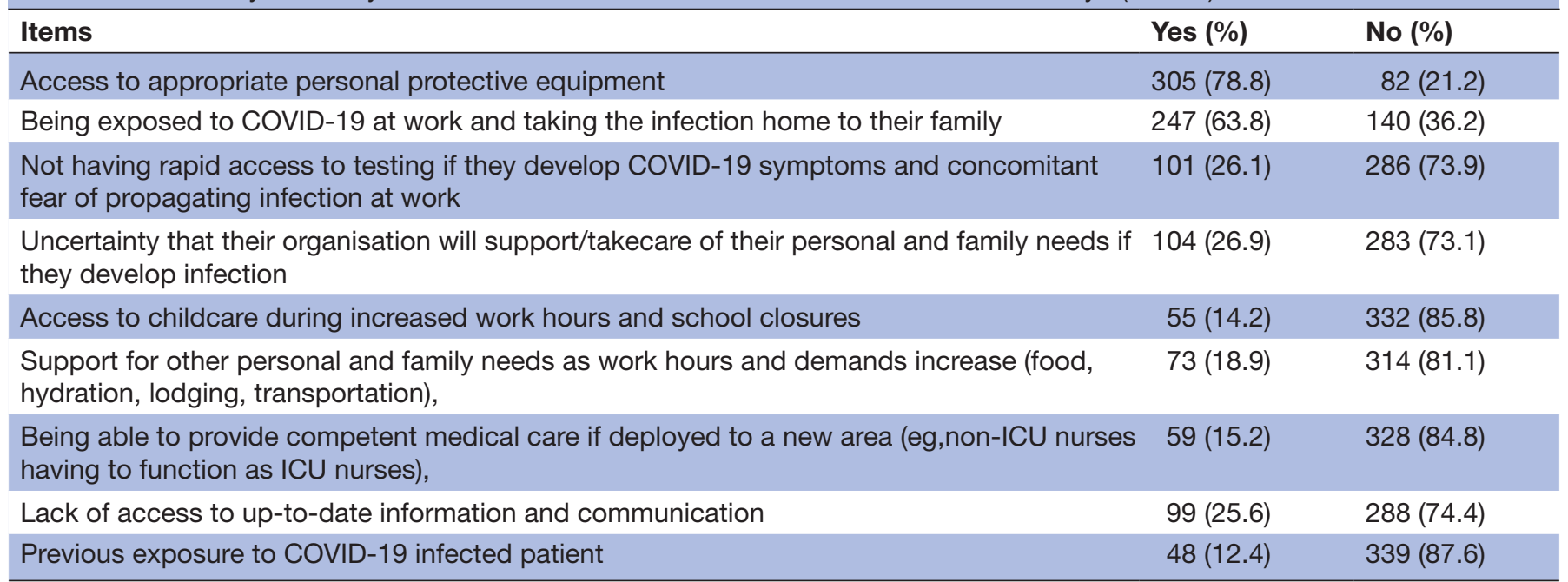

$\mathrm{ICU}$, intensive care unit.

\section{Common source of fear or anxiety in HCPs}

Among the most common causes of anxiety, fear or psychological distress that health professionals reported were lack of access to PPEs 305 (78.8\%), followed by being exposed to COVID-19 at work and taking the infection home to their family $247(63.8 \%)$ and uncertainty that their organisation will support/takecare of their personal and family needs if they develop infection $104(26.9 \%)$ as shown in table 2.

\section{Prevalence of mental health problems}

The prevalence of depression, anxiety and stress symptoms among HCPs were $50.1 \%, 55.0 \%$ and $38.5 \%$, respectively (figure 1).

Moreover, 41 (10.6\%) and $44(11.4 \%)$ participants had severe and extremely severe level of depressive symptoms. One out of five, $88(22.7 \%)$ and $20(5.2 \%)$, participants had extremely severe level symptoms of anxiety and stress, respectively (table 3 ).

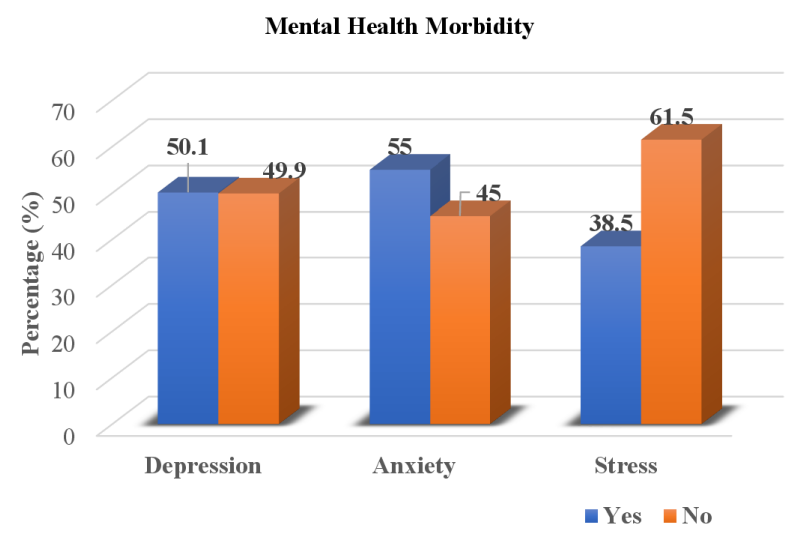

Figure 1 Prevalence of mental health problems of the study participants during COVID-19 pandemic in selected hospitals of Sidama National Regional State, 2020 ( $n=387)$.
Independent predictors of mental health problems

Being female (AOR 3.71, 95\% CI 2.31 to 5.97), married (AOR 2.28, 95\% CI 1.34 to 3.86), living alone (AOR 1.87, 95\% CI 1.09 to 3.20), nurses (AOR 2.94, 95\% CI 1.44 to 5.99), and working in inpatients (AOR $0.53,95 \%$ CI 0.29 to 0.93 ) were significantly associated with depressive symptoms (table 4 ).

Moreover, older age groups (AOR 3.15, 95\% CI 1.04 to 6.56), females (AOR 3.25, 95\% CI 2.01 to 5.25), married (AOR 1.69, 95\% CI 1.01 to 2.87) and nurses (AOR 3.32, 95\% CI 1.63 to 6.78 ) were significantly associated with symptoms of anxiety (table 5 ).

Stress symptoms were significantly high among females (AOR 2.47, 95\% CI 1.53 to 3.97), married (AOR 2.77, 95\% CI 1.60 to 4.78 ), living alone (AOR 2.01, 95\% CI 1.15 to 3.52 ), nurses (AOR 2.34, 95\% CI 1.11 to 4.92 ) and working in units other than emergency unit (impatient (AOR $0.32,95 \%$ CI 0.18 to 0.57 ) and other units (AOR $0.48,95 \%$ CI 0.25 to 0.95$)$ ) as indicated in table 6 .

\section{DISCUSSION}

As far as the best of our knowledge, this is one of the first few studies in southern Ethiopia which examines the adverse outcomes of mental health among HCPs during COVID-19. The psychological reaction of HCPs to an outbreak of infectious diseases is complex and may be influenced by a variety of factors. In our study, the most common sources of fear/anxiety were a lack of access to PPEs $78.8 \%$, fear of being exposed to COVID-19 at work and spreading the infection to their family $63.8 \%$, and uncertainty that their organisation will support/take care of their personal and family needs if they become infected $26.9 \%$ as reported in previous studies. ${ }^{7}$

In our study, the prevalence of symptoms of depression, anxiety and stress is $50.1 \%, 55.0 \%$ and $38.5 \%$, respectively. The magnitude of depressive symptoms in this 
Table 3 Severity level of mental health problems of the study participants during COVID-19 pandemic in selected hospitals of Sidama National Regional State, 2020 ( $n=387)$

\begin{tabular}{llllll}
\hline & Normal (\%) & Mild (\%) & Moderate (\%) & Seve (\%)re & $\begin{array}{l}\text { Extremely severe } \\
\text { (\%) }\end{array}$ \\
\hline Depression & $193(49.9)$ & $47(12.1)$ & $62(16.0)$ & $41(10.6)$ & $44(11.4)$ \\
Anxiety & $174(45.0)$ & $42(10.9)$ & $41(10.6)$ & $42(10.9)$ & $88(22.7)$ \\
Stress & $238(61.5)$ & $42(10.9)$ & $47(12.1)$ & $40(10.3)$ & $20(5.2)$ \\
\hline
\end{tabular}

study was nearly consistent with studies in (Libya $56.3 \%,{ }^{22}$ China $(50.4 \%),{ }^{23}$ Spain $(46 \%),{ }^{24}$ Canada $(44 \%)^{25}$ and Bangladesh (44\%). ${ }^{26}$ But, other findings from northern Ethiopia $(58.2 \%)^{15}$ and Turkey $(76.6 \%)^{27}$ showed higher prevalence of depressive symptoms than our result. And also, previous results from India $(11.4 \%),{ }^{28}$ Singapore $(8.9 \%)^{11}$ and Malaysia $(21.8 \%)^{29}$ indicated lower prevalence of depressive symptoms. The explanation for the disparity could be due to a simple size difference,

Table 4 Factors associated with symptoms of depression of the study participants during COVID-19 pandemic in selected hospitals of Sidama National Regional State, $2020(n=387)$

\begin{tabular}{|c|c|c|c|c|c|}
\hline \multirow[b]{2}{*}{ Variable } & \multirow[b]{2}{*}{ Category } & \multicolumn{2}{|c|}{ Depression } & \multirow[b]{2}{*}{ AOR $(95 \% \mathrm{Cl})$} & \multirow[b]{2}{*}{ COR (95\% Cl) } \\
\hline & & Yes & No & & \\
\hline \multirow[t]{3}{*}{ Age } & $<25$ years & 53 & 58 & 1 & 1 \\
\hline & $26-35$ years & 127 & 118 & 1.01 (0.65 to 1.59$)$ & $0.83(0.47$ to 1.46$)$ \\
\hline & $\geq 36$ years & 14 & 17 & $2.78(1.29 \text { to } 5.98)^{*}$ & 2.33 (0.84 to 6.50$)$ \\
\hline \multirow[t]{2}{*}{ Sex } & Male & 84 & 143 & 1 & 1 \\
\hline & Female & 110 & 50 & $3.75(2.44 \text { to } 5.75)^{\star}$ & $3.71(2.31 \text { to } 5.97)^{\star}$ \\
\hline \multirow[t]{3}{*}{ Marital status } & Single & 74 & 111 & 1 & 1 \\
\hline & Married & 116 & 75 & $2.32(1.54 \text { to } 3.51)^{\star}$ & $2.28(1.34 \text { to } 3.86)^{*}$ \\
\hline & Divorced & 4 & 7 & 0.85 (0.24 to 3.03$)$ & 0.73 (0.17 to 3.00$)$ \\
\hline \multirow[t]{3}{*}{ Educational status } & Diploma & 27 & 20 & 2.19 (0.94 to 5.13$)$ & 1.18 (0.43 to 3.27$)$ \\
\hline & BSc degree & 151 & 147 & 1.67 (0.86 to 3.24$)$ & 1.10 (0.50 to 2.42$)$ \\
\hline & MSc degree & 16 & 26 & 1 & 1 \\
\hline \multirow[t]{2}{*}{ Average monthly income } & $<7000$ ETB & 119 & 114 & 1.10 (0.73 to 1.65$)$ & 0.87 (0.49 to 1.53$)$ \\
\hline & $\geq 7000$ ETB & 75 & 79 & 1 & 1 \\
\hline \multirow[t]{3}{*}{ Work experience in years } & $\leq 5$ years & 103 & 127 & 0.57 (0.28 to 1.18$)$ & 1.65 (0.62 to 4.42$)$ \\
\hline & $6-10$ years & 70 & 51 & 0.98 (0.46 to 2.08$)$ & $1.66(0.67$ to 4.14$)$ \\
\hline & $\geq 11$ years & 21 & 15 & 1 & 1 \\
\hline \multirow[t]{3}{*}{ Living status } & With family & 114 & 110 & 1 & 1 \\
\hline & Alone & 69 & 74 & 0.85 (0.34 to 2.13 ) & $1.87(1.09$ to 3.20$)$ * \\
\hline & With others & 11 & 9 & 0.76 (0.29 to 1.95$)$ & 2.13 (0.73 to 6.17$)$ \\
\hline \multirow[t]{3}{*}{ Profession } & Physician & 30 & 58 & 1 & 1 \\
\hline & Nurses & 122 & 75 & $3.14(1.86 \text { to } 5.32)^{\star}$ & $2.94(1.44 \text { to } 5.99)^{\star}$ \\
\hline & Other professionals $†$ & 42 & 60 & 1.35 (0.75 to 2.44$)$ & 1.46 (0.72 to 2.96$)$ \\
\hline \multirow[t]{4}{*}{ Working environment } & Emergency & 78 & 60 & 1 & 1 \\
\hline & Inpatient units & 53 & 67 & $0.61(0.37 \text { to } 0.99)^{\star}$ & $0.53(0.29 \text { to } 0.93)^{\star}$ \\
\hline & OPD & 26 & 32 & 0.63 (0.34 to 1.56$)$ & 0.79 (0.38 to 1.61$)$ \\
\hline & Others $\ddagger$ & 37 & 34 & 0.84 (0.47 to 1.49$)$ & 1.00 (0.52 to 1.96$)$ \\
\hline
\end{tabular}

${ }^{*} \mathrm{P}<0.05$.

†Public health officers, laboratory, midwives, pharmacists.

‡Delivery, laboratory, pharmacy, ART clinics, TB clinics, etc.

.AOR, adjusted odds ratio; ART, Antiretroviral; BSc, Bachelor of Science ; COR, Crude odds ratio; ETB, Ethiopian Birr; MSc, Master of

Science ; OPD, outpatient department. 
Table 5 Factors associated with symptoms of anxiety of the study participants during COVID-19 pandemic in selected hospitals of Sidama National Regional State, $2020(n=387)$

\begin{tabular}{|c|c|c|c|c|c|}
\hline \multirow[b]{2}{*}{ Variable } & \multirow[b]{2}{*}{ Category } & \multicolumn{2}{|c|}{ Anxiety } & \multirow[b]{2}{*}{ AOR $(95 \% \mathrm{Cl})$} & \multirow[b]{2}{*}{ COR $(95 \% \mathrm{Cl})$} \\
\hline & & Yes & No & & \\
\hline \multirow[t]{2}{*}{ Age } & $<25$ years & 58 & 53 & 1 & 1 \\
\hline & $\geq 36$ years & 19 & 12 & $4.65(1.91 \text { to } 11.36)^{\star}$ & $3.15(1.04 \text { to } 6.56)^{*}$ \\
\hline Sex & Male & 98 & 129 & 1 & 1 \\
\hline \multirow[t]{3}{*}{ Marital status } & Single & 86 & 99 & 1 & 1 \\
\hline & Married & 122 & 69 & $2.03(1.35 \text { to } 3.08)^{*}$ & $1.69(1.01 \text { to } 2.87)^{\star}$ \\
\hline & Divorced & 5 & 6 & $0.96(0.28$ to 3.25$)$ & $0.69(0.17$ to 2.75$)$ \\
\hline Educational status & Diploma & 31 & 16 & $1.76(0.75$ to 4.14$)$ & 0.90 (0.33 to 2.48$)$ \\
\hline Average monthly income & $\geq 7000$ ETB & 82 & 72 & 1 & 1 \\
\hline \multirow[t]{3}{*}{ Work experience in years } & $\leq 5$ years & 112 & 118 & $0.27(0.12 \text { to } 0.62)^{\star}$ & 0.81 (0.28 to 2.31) \\
\hline & $6-10$ years & 73 & 48 & $0.43(0.18$ to 1.03$)$ & $0.74(0.27$ to 1.99$)$ \\
\hline & $\geq 11$ years & 28 & 8 & 1 & 1 \\
\hline \multirow[t]{3}{*}{ Living status } & With family & 128 & 96 & 1 & 1 \\
\hline & Alone & 73 & 70 & 0.78 (0.51 to 1.19$)$ & 1.55 (0.62 to 2.63$)$ \\
\hline & With others & 12 & 8 & $1.13(0.44$ to 2.86$)$ & 2.04 (0.69 to 5.95) \\
\hline \multirow[t]{2}{*}{ Profession } & Physician & 33 & 55 & 1 & 1 \\
\hline & Nurses & 133 & 64 & $3.46(2.05 \text { to } 5.85)^{\star}$ & $3.32(1.63 \text { to } 6.78)^{\star}$ \\
\hline
\end{tabular}

${ }^{*} \mathrm{P}<0.05$.

†Public health officers, laboratory, midwives, pharmacists.

‡Delivery, laboratory, pharmacy, ART (antiretroviral) clinics, TB (tuberculosis) clinics, etc.

AOR, Adjusted odds ratio; BSc, Bachelor of Science; COR, Crude odds ratio; ETB, Ethiopian Birr; MSc, Master of Science; OPD, outpatient department.

a depression diagnostic technique or the research time period.

Similarly, the prevalence of anxiety symptoms in this study was similar to studies in Turkey $(60.2 \%),{ }^{27}$ Spain $(58.6 \%)^{24}$ and Ethiopia $(64.7 \%) .{ }^{15}$ Conversely, the prevalence of anxiety symptoms was higher than the studies conducted in India (17.7\%), ${ }^{28}$ Singapore $(14.5 \%),{ }^{11}$ Nepal $38 \%{ }^{30}$ and Ethiopia (26.8\%). ${ }^{12}$ The disparity could be attributed to differences in the anxiety assessment tool used, the cut-off values used to categorise the outcome and the magnitude of COVID-19. In general, HCPs appear to be suffering from extensive mental health concerns during the COVID-19 epidemic. ${ }^{31}{ }^{32}$ Both before and after the epidemic, HCPs have a high demand for mental healthcare. The significant prevalence of mental health problems confirmed with this study and other previous studies ${ }^{13-1533} 34$ suggests that HCPs in Ethiopia will require mental health and psychosocial support (MHPSS) in the future. Thus, in order to better prevent and control the COVID-19 pandemic, it is necessary to address mental health issues among HCPs.

In addition, the prevalence of stress symptoms was in line with studies in Spain $(41.1 \%)^{24}$ and Turkey $\left.(41.2 \%)\right)^{35}$ Contrary to this finding higher results were reported in previous studies in different parts of Ethiopia $(51.6 \%$ $78.3 \%),{ }^{13-15}$ Turkey $(76.4 \%)^{27}$ and Canada $(85.6 \%) .{ }^{25}$ The disparity could be due to a difference in sample size, the time the research was conducted, the level of development of health services, or prior experience with comparable pandemics. In general, the degree of mental health 
Table 6 Factors associated with symptoms of stress of the study participants during COVID-19 pandemic in selected hospitals of Sidama National Regional State, $2020(n=387)$

\begin{tabular}{|c|c|c|c|c|c|}
\hline \multirow[b]{2}{*}{ Variable } & \multirow[b]{2}{*}{ Category } & \multicolumn{2}{|c|}{ Stress } & \multirow[b]{2}{*}{ AOR $(95 \% \mathrm{Cl})$} & \multirow[b]{2}{*}{ COR (95\% Cl) } \\
\hline & & Yes & No & & \\
\hline \multirow[t]{2}{*}{ Age } & $<25$ years & 39 & 72 & 1 & 1 \\
\hline & $\geq 36$ years & 13 & 18 & $2.26(1.10 \text { to } 4.66)^{*}$ & $1.86(0.71$ to 4.88$)$ \\
\hline Sex & Male & 66 & 161 & 1 & 1 \\
\hline \multirow[t]{3}{*}{ Marital status } & Single & 51 & 134 & 1 & 1 \\
\hline & Married & 95 & 96 & $2.60(1.69 \text { to } 3.99)^{*}$ & $2.77(1.60 \text { to } 4.78)^{*}$ \\
\hline & Divorced & 3 & 8 & $0.98(0.25$ to 3.86$)$ & 1.05 (0.24 to 4.61$)$ \\
\hline Educational status & Diploma & 23 & 24 & 2.39 (0.99 to 5.78$)$ & 1.23 (0.43 to 3.54$)$ \\
\hline Average monthly income & $\geq 7000$ ETB & 53 & 101 & 1 & 1 \\
\hline \multirow[t]{3}{*}{ Work experience in years } & $\leq 5$ years & 76 & 154 & $0.49(0.24$ to 1.00$)$ & 0.84 (0.32 to 2.19$)$ \\
\hline & $6-10$ years & 55 & 66 & 0.83 (0.39 to 1.75$)$ & $0.99(0.41$ to 2.37$)$ \\
\hline & $\geq 11$ years & 18 & 18 & 1 & 1 \\
\hline \multirow[t]{3}{*}{ Living status } & With family & 87 & 137 & 1 & 1 \\
\hline & Alone & 53 & 90 & $0.93(0.60$ to 1.43$)$ & $2.01(1.15$ to 3.52$)$ * \\
\hline & With others & 9 & 11 & $1.28(0.51$ to 3.24$)$ & 2.48 (0.86 to 7.18$)$ \\
\hline \multirow[t]{2}{*}{ Profession } & Physician & 21 & 67 & 1 & 1 \\
\hline & Nurses & 99 & 98 & $3.22(1.83 \text { to } 5.66)^{*}$ & $2.34(1.11 \text { to } 4.92)^{\star}$ \\
\hline
\end{tabular}

${ }^{*} \mathrm{P}<0.05$.

†Public health officers, laboratory, midwives, pharmacists.

‡Delivery, laboratory, pharmacy, ART (antiretroviral) clinics, TB (tuberculosis) clinics, etc.

$\S$

AOR, Adjusted odds ratio; BSc, Bachelor of Science; COR, Crude odds ratio; ETB, Ethiopian Birr; MSc, Master of Science ; OPD, outpatient department.

problems varies greatly between researches, with $27.5 \%-$ $50.7 \%, 45 \%$ and $18.1 \%-80.1 \%$ of HCPs developing symptoms of depression, anxiety and stress, respectively. ${ }^{36}$ The use of different scales, the use of diverse testing procedures and methodology in research, as well as the use of different classifications, contribute to widely disparate estimations of the prevalence of mental disorders. ${ }^{37}$ Thus, HCPs appear to be suffering from extensive mental health concerns during the COVID-19 pandemic. Both during and after the pandemic, HCPs have a high demand for mental healthcare. The significant prevalence of mental health difficulties discovered in this study suggests that HCPs in Ethiopia will require mental healthcare in the future.
Females had higher levels of depression, anxiety and distress in this study which could be attributed to the previously reported gender difference in internalising mental disorders such as anxiety and depression. ${ }^{38} 39$ Burnout, anxiety and depression were all observed to be significantly greater in female responders in earlier investigations as well. ${ }^{40}$ Recent studies on COVID-19 health outcomes in HCPs consistently reveal a large proportion of mental health issues, particularly among women. ${ }^{41-43}$ Furthermore, women were more likely than men to suffer from despair, anxiety and somatisation symptoms as a result of the challenging work environment. ${ }^{44} \mathrm{On}$ the one hand, because of the typical culturally bound multiple duties of women in home, child care and skilled 
employment, women may have felt the pressure of working in the COVID-19 situation more than their male colleagues.

We also discovered that older employees reported higher levels of anxiety than their younger employees. This could be because the belief that COVID-19 is more serious and complicated in older age groups in the early era of the pandemic. Contrary to our result, recent research on COVID-19 health outcomes indicated, younger doctors have higher levels of insomnia and negative sleep patterns, ${ }^{45}$ as well as higher levels of stress. ${ }^{46}$ In addition, previous research has shown that less experienced HCPs are more prone to emotional distress symptoms than their more experienced counterparts. ${ }^{47} 48$

In comparison with physicians, our research has indicated that nurses are very likely to suffer from depression, anxiety and stress. Workloads and night shifts in healthcare, as well as contact with hazardous patients, enhance the risk of mental distress in nurses. ${ }^{49}$ The nursing staff have more and closer interaction with patients than other professionals, providing round-the-clock care required by patients with COVID-19. As a result, these findings highlight the importance of focusing on nursing staff to identify, treat, and, ideally, avoid anxiety through monitoring and screening. ${ }^{44}$ On the other hand, physicians may have a distinct resistance to somatisation, which can be related to personal accomplishment, ${ }^{50}$ professional experience and self-awareness. ${ }^{51}$ Another important reason could be that nurses have more physical contact with patients while providing care than doctors in hospital units. ${ }^{52}$

Our research found that HCPs who worked in nonemergency units were less likely to develop depression and stress than those who worked in emergency units as reported in previous study. ${ }^{44}$ This may be due to the fact that very polluted and dangerous emergency unit region is the so-called red zone, where most HCPs in front-line operate routinely. Moreover the loss of one patient may have occurred at half of doctors, nurses and technicians due to a pandemic or other medical crisis, including loss of their patients. While the loss of a patient incidence has been demonstrated to be one of the most common sources of stress among HCPs in any medical context notably in emergency departments. ${ }^{53} 54$

We found out that those HCPs who lived alone had significant levels of depression and stress. Consistent SARS outbreak studies show that the assistance of family and friends plays a significant role in preventing stress. ${ }^{55}$ Prior research has shown that good social and family support protects against acute stress and has a positive effect on their overall functioning over time.$^{55}$ During lockdown, it's typical to feel lonely and alienated from others, and regularly communicating with friends and family via video or phone calls can help to boost social support and reduce melancholy and stress. ${ }^{57}$

HCPs who were married were more likely to develop depression, anxiety, and stress in our study. A similar finding was observed in a recent case control investigation of HCWs dealing with the COVID-19 pandemic, which revealed that married operators had higher levels of stress symptoms than unmarried HCPs. ${ }^{58}$ This could be because married HCPs are concerned about getting exposed to COVID-19 at work and infecting their loved ones and children.

\section{Limitation of the study}

There are some limitations to this study. First, depression, anxiety and stress were assessed solely through self-administered questionnaires rather than through a psychiatric interview. Second, because we were unable to meet with HCPs face to face, we were unable to obtain detailed information about psychiatric symptoms history. Finally, this is a cross-sectional study. Longitudinal research on the prevalence of these mental states in the COVID-19 pandemic process is required. Fourth, no information on the type of mental health support received by HCWs could be obtained.

\section{CONCLUSION}

To summarise, we wanted to look into the prevalence of mental health issues among HCWs during the COVID-19 pandemic. We revealed that depression, anxiety and stress symptoms were the highly prevalent mental disorders experienced by HCPs. Being female, married, living alone, nurses and working in inpatients were significantly associated with depressive symptoms. Moreover, older age groups, females, married and nurses were more likely to develop symptoms of anxiety. Stress symptoms were significantly high among females, married, living alone, nurses and working in units other than emergency unit (impatient and other units). Therefore, taking steps to protect the mental health of HCPs is a crucial part of the public health response to the COVID-19 outbreak. Special interventions must be adopted to enhance mental wellbeing among COVID-19-affected HCPs and to reduce the pandemic's existing mental health consequences such as physical activity, peer support, adequate rest, tea or coffee break during working hours, meditation or religious or spiritual practices. HCPs require mental healthcare during and after the pandemic so that monitoring and control may be carried out. Furthermore, it would be preferable if the Ministry of Health and other relevant entities provided MHPSS to HCPs, as well as organising in-service training to promote awareness.

Correction notice This article has been corrected since it first published. 'OVID-19' has been changed to 'COVID-19' at the beginning of the introduction section.

Acknowledgements We would like to thank Hawassa University for providing funding for this study. Our heartfelt gratitude also goes to the data collectors and participants for their valuable contributions to the study process.

Contributors MA, BD, YA, YR and FT participated in the conception and design of the study, involved in the data collection and analysis of the study. SD, DH and TA were involved in the analysis of the study. MA prepared the manuscript for publication. BD, YA, YR, FT, SD, DH and TA critically reviewed the manuscript. MA is responsible for the overall content as guarantor. All authors read and approved the final manuscript.

Funding Hawassa University was funding to carry out this study. 
Competing interests None declared.

Patient and public involvement Patients and/or the public were not involved in the design, or conduct, or reporting, or dissemination plans of this research.

\section{Patient consent for publication Not applicable.}

Ethics approval Ethical approval and clearance were obtained from Hawassa University, College of Medicine and Health Sciences, Institutional Review Board (IRB) with reference number IRB/295/12. The same permission letter was written by the university to each health institution. The purpose of the study was explained for the respondents and consent was obtained. The right to withdraw from the study at any time was assured. Coding was used to eliminate names and other personal identification of respondents throughout the study process to ensure participants confidentiality.

Provenance and peer review Not commissioned; externally peer reviewed.

Data availability statement All data relevant to the study are included in the article or uploaded as online supplemental information. Not Applicable.

Open access This is an open access article distributed in accordance with the Creative Commons Attribution Non Commercial (CC BY-NC 4.0) license, which permits others to distribute, remix, adapt, build upon this work non-commercially, and license their derivative works on different terms, provided the original work is properly cited, appropriate credit is given, any changes made indicated, and the use is non-commercial. See: http://creativecommons.org/licenses/by-nc/4.0/.

\section{ORCID IDs}

Mohammed Ayalew http://orcid.org/0000-0001-9973-5741

Yared Reta http://orcid.org/0000-0002-8509-2287

\section{REFERENCES}

1 Wang C, Horby PW, Hayden FG, et al. A novel coronavirus outbreak of global health concern. Lancet 2020;395:470-3.

2 Mahase E. China coronavirus: WHO declares international emergency as death Toll exceeds 200. BMJ 2020;368:m408.

3 National Public Health Emergency Operation Center (Pheoc) E. Covid-19 pandemic preparedness and response in Ethiopia: weekly Bulletin, Epi-Week- 43 (October 25 - 31, 2021. EPHI, 2021: 1-20.

4 Xiang Y-T, Yang Y, Li W, et al. Timely mental health care for the 2019 novel coronavirus outbreak is urgently needed. Lancet Psychiatry 2020;7:228-229.

5 Dubey S, Biswas P, Ghosh R, et al. Psychosocial impact of COVID-19. Diabetes Metab Syndr 2020;14:779-88.

6 Huang Y, Zhao N. Generalized anxiety disorder, depressive symptoms and sleep quality during COVID-19 outbreak in China: a web-based cross-sectional survey. Psychiatry Res 2020;288:112954.

7 Elkholy H, Tawfik F, Ibrahim I, et al. Mental health of frontline healthcare workers exposed to COVID-19 in Egypt: a call for action. Int J Soc Psychiatry 2021;67:522-31.

8 Saragih ID, Tonapa SI, Saragih IS, et al. Global prevalence of mental health problems among healthcare workers during the Covid-19 pandemic: a systematic review and meta-analysis. Int J Nurs Stud 2021;121:104002.

9 Liu S, Yang L, Zhang C, et al. Online mental health services in China during the COVID-19 outbreak. Lancet Psychiatry 2020;7:e17-18.

10 Wang C, Pan R, Wan X, et al. Immediate psychological responses and associated factors during the initial stage of the 2019 coronavirus disease (COVID-19) epidemic among the general population in China. Int J Environ Res Public Health 2020;17:1729.

11 Tan BYQ, Chew NWS, Lee GKH, et al. Psychological impact of the COVID-19 pandemic on health care workers in Singapore. Ann Intern Med 2020;173:317-20.

12 Dagne $\mathrm{H}$, Atnafu A, Alemu K, et al. Anxiety and associated factors among Ethiopian health professionals at early stage of COVID-19 pandemic in Ethiopia. PLoS One 2021;16:e0252664

13 Yitayih Y, Mekonen S, Zeynudin A, et al. Mental health of healthcare professionals during the early stage of the COVID-19 pandemic in Ethiopia. BJPsych Open 2021;7:e1.

14 Chekole YA, Yimer Minaye S, Mekonnen Abate S, et al. Perceived stress and its associated factors during COVID-19 among healthcare providers in Ethiopia: a cross-sectional study. Adv Public Health 2020;2020:1-7.

15 Asnakew S, Amha H, Kassew T. Mental health adverse effects of COVID-19 pandemic on health care workers in North West Ethiopia: a multicenter cross-sectional study. Neuropsychiatr Dis Treat 2021;17:1375-84.
16 Tiong WW KG. Ethical considerations in the review of Singapore's H1N1 pandemic response framework in 2009. Ann Acad Med Singapore 2013;42:246-50.

17 Chan AOM. Psychological impact of the 2003 severe acute respiratory syndrome outbreak on health care workers in a medium size regional General Hospital in Singapore. Occup Med 2004;54:190-6.

18 Kang P, Lv Y, Hao L, et al. Psychological consequences and quality of life among medical rescuers who responded to the 2010 Yushu earthquake: a neglected problem. Psychiatry Res 2015;230:517-23.

19 Liu Y-hua, Yang H-ning, Liu H-liang, et al. [Medical rescue of China National Earthquake Disaster Emergency Search and Rescue Team in Lushan earthquake]. Zhonghua Wei Zhong Bing Ji Jiu Yi Xue 2013;25:265-7

20 Le TA, Le MQT, Dang AD, et al. Multi-Level predictors of psychological problems among methadone maintenance treatment patients in difference types of settings in Vietnam. Subst Abuse Treat Prev Policy 2019;14:39.

21 Lovibond SH, Lovibond PF. Manual for the depression anxiety stress scales. 2nd edn. Sydney: Psychology Foundation, 1995.

22 Elhadi M, Msherghi A, Elgzairi M, et al. Psychological status of healthcare workers during the civil war and COVID-19 pandemic: a cross-sectional study. J Psychosom Res 2020;137:110221.

23 Lai J, Ma S, Wang Y, et al. Factors associated with mental health outcomes among health care workers exposed to coronavirus disease 2019. JAMA Netw Open 2020;3:e203976.

24 Luceño-Moreno L, Talavera-Velasco B, García-Albuerne Y, et al. Symptoms of posttraumatic stress, anxiety, depression, levels of resilience and burnout in Spanish health personnel during the COVID-19 pandemic. Int J Environ Res Public Health 2020;17:5514.

25 Mrklas K, Shalaby R, Hrabok M, et al. Prevalence of perceived stress, anxiety, depression, and obsessive-compulsive symptoms in health care workers and other workers in Alberta during the COVID-19 pandemic: cross-sectional survey. JMIR Ment Health 2020;7:e22408.

26 Repon MAU, Pakhe SA, Quaiyum S, et al. Effect of COVID-19 pandemic on mental health among Bangladeshi healthcare professionals: a cross-sectional study. Sci Prog 2021;104:003685042110264-18.

27 Sahin MK, Aker S, Sahin G, et al. Prevalence of depression, anxiety, distress and insomnia and related factors in healthcare workers during COVID-19 pandemic in turkey. J Community Health 2020;45:1168-77.

28 Wilson W, Raj JP, Rao S, et al. Prevalence and predictors of stress, anxiety, and depression among healthcare workers managing COVID-19 pandemic in India: a nationwide observational study. Indian J Psychol Med 2020;42:353-8.

29 Woon LS-C, Sidi H, Nik Jaafar NR, et al. Mental health status of university healthcare workers during the COVID-19 pandemic: a Post-Movement Lockdown assessment. Int J Environ Res Public Health 2020;17:9155.

30 Gupta AK, Mehra A, Niraula A, et al. Prevalence of anxiety and depression among the healthcare workers in Nepal during the COVID-19 pandemic. Asian J Psychiatr 2020;54:102260.

31 Mohamad-Hani Temsah SA. Understanding the Psychological Stress and Optimizing the Psychological Support for the Acute - Care Health - Care Workers during the COVID - 19 Pandemic. Saudi Crit Care J 2020;4:25-7.

32 AlAteeq DA, Aljhani S, Althiyabi I, et al. Mental health among healthcare providers during coronavirus disease (COVID-19) outbreak in Saudi Arabia. J Infect Public Health 2020;13:1432-7.

33 Asnakew S, Legas G, Muche Liyeh T, et al. Prevalence of posttraumatic stress disorder on health professionals in the era of COVID-19 pandemic, Northwest Ethiopia, 2020: a multi-centered cross-sectional study. PLoS One 2021;16:e0255340.

34 Jemal K, Deriba BS, Geleta TA. Psychological distress, early behavioral response, and perception toward the COVID-19 pandemic among health care workers in North Shoa zone, Oromiya region. Front Psychiatry 2021;12:1-12.

35 Elbay RY, Kurtulmuș A, Arpacioğlu S, et al. Depression, anxiety, stress levels of physicians and associated factors in Covid-19 pandemics. Psychiatry Res 2020;290:113130.

36 Preti E, Di Mattei V, Perego G, et al. The psychological impact of epidemic and pandemic outbreaks on healthcare workers: rapid review of the evidence. Curr Psychiatry Rep 2020;22:1-22.

37 Pappa S, Ntella V, Giannakas T, et al. Prevalence of depression, anxiety, and insomnia among healthcare workers during the COVID-19 pandemic: a systematic review and meta-analysis. Brain Behav Immun 2020;88:901-7.

38 Lai J, Ma S, Wang Y, et al. Factors associated with mental health outcomes among health care workers exposed to coronavirus disease 2019. JAMA Netw Open 2020;3:e203976. 
39 Zhang W-R, Wang K, Yin L, et al. Mental health and psychosocial problems of medical health workers during the COVID-19 epidemic in China. Psychother Psychosom 2020;89:242-50.

40 Civantos AM, Byrnes Y, Chang C, et al. Mental health among otolaryngology resident and attending physicians during the COVID-19 pandemic: national study. Head Neck 2020;42:1597-609.

41 Luo M, Guo L, Yu M, et al. The psychological and mental impact of coronavirus disease 2019 (COVID-19) on medical staff and general public - A systematic review and meta-analysis. Psychiatry Res 2020;291:113190.

42 Rossi R, Socci V, Pacitti F, et al. Mental health outcomes among frontline and second-line health care workers during the coronavirus disease 2019 (COVID-19) pandemic in Italy. JAMA Netw Open 2020;3:e2010185

43 Barello S, Palamenghi L, Graffigna G. Burnout and somatic symptoms among frontline healthcare professionals at the peak of the Italian COVID-19 pandemic. Psychiatry Res 2020;290:113129.

44 Conti C, Fontanesi L, Lanzara R, et al. Fragile heroes. The psychological impact of the COVID-19 pandemic on health-care workers in Italy. PLoS One . 2020;15:1-17.

45 Abdulah DM, Musa DH. Insomnia and stress of physicians during COVID-19 outbreak. Sleep Med 2020;2:100017.

46 Romero CS, Delgado C, Catalá J, et al. COVID-19 psychological impact in 3109 healthcare workers in Spain: the PSIMCOV group. Psychol Med 2020:1-7.

47 Wurm W, Vogel K, Holl A, et al. Depression-Burnout overlap in physicians. PLoS One 2016;11:e0149913.

48 Zhou J, Yang Y, Qiu X, et al. Relationship between anxiety and burnout among Chinese physicians: a moderated mediation model. PLoS One 2016;11:e0157013.
49 Zhang C, Yang L, Liu S, et al. Survey of insomnia and related social psychological factors among medical staff involved in the 2019 novel coronavirus disease outbreak. Front Psychiatry 2020;11:306.

50 Zwack J, Schweitzer J. If every fifth physician is affected by burnout, what about the other four? Resilience strategies of experienced physicians. Acad Med 2013;88:382-9.

51 Zwack J, Abel C, Schweitzer J. [Physicians' resilience--salutogenetic practices and attitudes of experienced physicians]. Psychother Psychosom Med Psychol 2011;61:495-502.

$52 \mathrm{Li} \mathrm{Y,} \mathrm{Zhang} \mathrm{H,} \mathrm{Feng} \mathrm{Z.} \mathrm{Life} \mathrm{events,} \mathrm{anxiety} \mathrm{and} \mathrm{depression} \mathrm{among}$ doctors and nurses in the emergency department: a study from eleven General Hospital in Hunan Province, China. J Psychiatr Brain Sci 2016;1.

53 Joliat G-R, Demartines N, Uldry E. Systematic review of the impact of patient death on surgeons. Br J Surg 2019;106:1429-32.

54 Carton ER HJ. The forgotten mourners: addressing health care provider grief-a systematic review. J Hosp Palliat Nurs 2014;16:291-303.

55 Su T-P, Lien T-C, Yang C-Y, et al. Prevalence of psychiatric morbidity and psychological adaptation of the nurses in a structured SARS caring unit during outbreak: a prospective and periodic assessment study in Taiwan. J Psychiatr Res 2007;41:119-30.

56 Chan AOM, Huak CY. Psychological impact of the 2003 severe acute respiratory syndrome outbreak on health care workers in a medium size regional General Hospital in Singapore. Occup Med 2004;54:190-6.

57 Bavel JJV, Baicker K, Boggio PS, et al. Using social and behavioural science to support COVID-19 pandemic response. Nat Hum Behav 2020;4:460-71.

$58 \mathrm{Li}$ Zet al. Vicarious traumatization in the general public, members, and non-members of. Brain Behav Immun S 2020:20:0889-1591. 